\title{
Preface to the Paperback Edition
}

Tn the eighteen years since this book was originally published, a great deal of new work on Frege has appeared. I would certainly write this book differently today, both because some of my views have changed and because some of the issues that were controversial in 1990 are no longer controversial. For all that, I think that this book deserves to stand in its original form, and I am delighted that it is being made available in a new paperback edition. Since I have made only a few small changes in the text, I would like to make some remarks in this preface to orient the contemporary reader and to ward off some potential misunderstandings.

The topic of Frege in Perspective is the single grand project to which Frege devoted nearly his entire career. I set out to explain this project and to provide a reading that shows how most of Frege's writings - including the articles that have typically been read as self-contained works in the philosophy of language - are meant to contribute to the project. My aim is to illuminate these articles as well as the central project. For, once these articles are read as contributions to the central project, we can see that many of Frege's views about language and logic are very different from those that had been traditionally attributed to him.

And what was Frege's project? To give gapless logical proofs of the basic truths of arithmetic - that is, proofs employing only primitive logical laws and definitions of the terms of arithmetic from primitive terms belonging to logic. But this is not the whole answer. We know, for instance, that Frege would not have accepted the axioms of Peano arithmetic as premises for the proofs in question. On Frege's view these axioms are not primitive logical laws, and numerals are not primitive terms belonging to logic. But why not? What are the primitive logical laws? What are the primitive terms belonging to logic and why are numerals not among them? What do definitions (particularly definitions of familiar terms of arithmetic) do? And how are we to determine whether a proof is gapless? 
The answers to these questions, I argue, are to be found by looking at Frege's epistemological concerns.

These epistemological concerns surface in Frege's first mention of the project, in the preface to Begriffsschrift. He characterizes the new logic he is introducing as a means for determining whether or not a particular truth "depends solely on those laws upon which all knowledge rests." (p. 5) He classifies judgments into two groups: those that require only logic for their justification and those that require, in addition, appeals to facts of experience. He tells us that it was his desire to show that the truths of arithmetic fall into the former group that led to the development of his new logic. One of the fruits of the new logic is his purely logical proof of mathematical induction in Begriffsschrift.

Several years later, in Foundations of Arithmetic, Frege describes his project in more detail. The two-part classification from Begriffsschrift has now become a three-part classification: truths are either analytic, synthetic a priori, or synthetic a posteriori. Frege views this three-part classification of truths, I argue in Frege in Perspective, in two ways. First, it marks out three sources of knowledge. Second, it describes a hierarchy of generality from the least general (synthetic a posteriori truths, which tell us only about the physical world) to the most general (analytic truths, which tell us about everything). In Foundations, Frege argues that the truths of arithmetic are analytic. But these arguments are not meant to be conclusive, as he tells us both in Foundations and in Basic Laws. The aim of Foundations is only to make the case that it is "probable that arithmetic is a branch of logic and need not borrow any ground of proof whatever from either experience or intuition," (Basic Laws, p. 1). To show that arithmetic is a branch of logic requires presuppositionless proofs. For, he writes, "It is indeed precisely the presuppositions made tacitly and without clear awareness that obstruct our insight into the epistemological nature of a law." (p. 1) The actual proofs were to be provided in Basic Laws.

We need an understanding of these concerns, which I (following Frege's characterization in section 3 of Foundations) call the "philosophical" motivation of his project, in order to answer important questions about the way in which Frege pursues his project. Such an understanding is required if we are to see why he insists on defining the number onewhy, more generally, he would not accept the numerals as primitive logical terms - and why he employs his odd standards for his definitions (for example, why he insists on rejecting definitions in terms of Cantor's sets). In pursuing this sort of understanding of why Frege adopted the standards he adopted, I follow Frege who, after saying that his purpose "necessitates many departures from what is customary in mathematics" (Basic Laws, p. 
vii) goes on to explain why his purpose leads him to reject Dedekind's definitions of the numbers.

My discussion of Frege's motivation for his project and, in particular, my comments about the role of mathematics in this motivation is one of the more controversial discussions in this book. I remain unapologetic about my use of the term "philosophical" (as opposed to "mathematical") to characterize the concerns just described. It is not just that Frege himself characterized them as philosophical and contrasted them with other, mathematical, concerns. Concerns about the sources of knowledge are philosophical concerns. And if some mathematicians - if some schools of mathematics - were engaged in projects driven by such concerns, it seems perfectly reasonable to say that these mathematicians too were driven by philosophical concerns.

However, I now regret one aspect of my treatment of Frege's motivation. When I wrote this book, the central point I wished to make about Frege's motivation for undertaking his project - one with which I remain entirely in agreement — was that an understanding of Frege's concern with sources of knowledge is required if we are to understand why Frege's mathematical project (to provide gapless proofs of the truths of arithmetic) takes the peculiar form it does. Thus when I wrote of "Frege's motivation for his project," I was talking about something very specific: a motivation that would account for the peculiar requirements Frege placed on his definitions, a motivation that would explain the role the notion of primitiveness plays in Frege's project. I argued that only a motivation that is philosophical (in the sense just described) would do this work. This led me to write, in the original version of this book, that Frege's project had "no convincing mathematical motivation". That was a mistake. It is entirely compatible with interpretation in this book that Frege should have had any number of additional motivations for writing what he did, including mathematical ones. For this edition, I have done what I could, consistent with not engaging in a major rewrite, to expunge those sentences in which I suggested otherwise.

One peculiarity that, I argue, is motivated by Frege's philosophical concerns is his refusal to count any statement about the numbers or the concept number as a primitive truth. As Frege's discussions in Chapter 1 of Foundations show, it is not obvious how to classify statements about numbers (i.e., to say whether they count as analytic, synthetic a priori, or synthetic a posteriori). The upshot, I argue, is that these statements cannot be regarded as primitive. For, on Frege's notion of primitiveness, the appropriate classification of a primitive truth must be obvious from its content. The argument for this last claim, however, was left out of Frege in Perspective. The argument is, briefly, as follows. 
Frege thinks that, to determine the epistemological status - that is, the appropriate classification - of the truths of arithmetic, what we need are presuppositionless proofs of the basic truths of arithmetic from primitive truths. Let us suppose, for the moment, that we have such proofs. The classification of the truths of arithmetic depends on the classification(s) of the primitive truths that are the premises of these proofs. But how are we to classify the primitive truths? Given that these truths do not require proof, there are two possibilities. Either the correct classification is evident from their content (that is, no further work is required) or there is some other procedure for determining the correct classification (that is, some further work is required). Frege's Foundations description of what is needed to categorize truths suggests the former. For he never suggests that, after finding a proof of a truth from primitive truths, we must engage in a further investigation of how the primitive truths should be classified. Nor does he himself engage in such investigations. Had Frege believed that further investigation was required to determine the categorization of primitive truths, his failure to engage in this further investigation would be inexplicable - particularly given his disagreement with Kant over the classifications of certain primitive truths. Thus I took it to be a hallmark of Frege's notion of primitiveness that the correct classification of a primitive truth (although not, in the case of a primitive a posteriori truth, the fact that it is a truth) is obvious from its content.

One of the significant departures from previous scholarship in the pages below is to be found in my account of the role elucidation plays in Frege's work. Frege mentions and discusses this notion in Basic Laws and in his essays on geometry. But its full significance for Frege's thought only emerges if we consider, also, the role this notion plays in his infamous discussion of the "concept horse" problem. Notoriously, Frege seems to commit himself, in full awareness, to a view of the notions of concept and function that is contradictory. He even characterizes the attempt to define the notion of function as "nonsense." Yet he also tells us that these notions are the foundation stones on which his logic is constructed. This is not to say that Frege understands his use of concept-and functionexpressions in Begriffsschrift to be inconsistent. He does not, and he is right not to do so. There is nothing contradictory about the use of these expressions in Begriffsschrift, once Basic Law V is removed. And, however confusing Frege's remarks about the notion of concept may be, most of us (even most undergraduates) have no difficulty using (a version of) his logic.

How could Frege have held these apparently conflicting attitudes? The answer, I try to show, lies in Frege's understanding of the notion of elucidation. Frege's general remarks about the notions of concept and function 
are no part of the logical theory. Rather, they are designed to be elucidatory remarks in a propaedeutic to the logic - remarks designed to get us to understand what the logic is doing and how it works. I argue that, because the remarks belong to the propaedeutic rather than to the theory, the fact that they are contradictory need not prevent them from being used to accomplish their elucidatory aim.

Some have taken this position to be one on which the propaedeutic of a theory must be nonsensical. But this does not follow, nor is it my view. There is no reason to think that elucidatory statements need be (or are in general) nonsensical or contradictory. One of Frege's contributions, I argue, is to make explicit the difference between contributions to the theory and contributions to the propaedeutic. Another is to make explicit which statements can serve as basic premises, or stopping points, of proofs in his systematic science. Many elucidatory statements are perfectly good statements that are not part of the theory. They are intelligible statements with which we begin when we describe the proofs of a systematic science, but they are not themselves basic premises of this science. Others turn out to be rough natural language versions of actual statements of the theory. What is required to achieve the goal of elucidation - that is, to play the psychological role of getting us to understand something - can be different from what is required to achieve the goal of setting out the necessary premises of a proof. This, I argue, is Frege's view. And one upshot of Frege's identification of an elucidatory role that is distinct from the role of statements of a theory is that there can be an elucidatory role for statements that are vague or even contradictory.

But, while I do think that this upshot is important, the focus on this upshot of Frege's notion of elucidation has obscured something else that is at least as important. This is Frege's attempt to identify the stopping point for proof. The issue of what we should count as a good stopping point in a proof or in a theory, as well as that of what considerations can and should influence our decisions, is every bit as important. Frege's choice of a stopping point for the theory of logic is determined by the nature of his search for the source of our knowledge of the truths of arithmetic. One of the central aims of this book is to provide a description of Frege's understanding of these issues and the conception of philosophy that lies behind it.

\section{Bloomington, Indiana}

JOAN WEINER 
